\title{
Brief Surgical Procedure Code Lists for Outcomes Measurement and Quality Improvement in Resource-Limited Settings
}

\section{Citation}

Liu, Charles. 2016. Brief Surgical Procedure Code Lists for Outcomes Measurement and Quality Improvement in Resource-Limited Settings. Doctoral dissertation, Harvard Medical School.

\section{Permanent link}

http://nrs.harvard.edu/urn-3:HUL.InstRepos:27007744

\section{Terms of Use}

This article was downloaded from Harvard University's DASH repository, and is made available under the terms and conditions applicable to Other Posted Material, as set forth at http:// nrs.harvard.edu/urn-3:HUL.InstRepos:dash.current.terms-of-use\#LAA

\section{Share Your Story}

The Harvard community has made this article openly available.

Please share how this access benefits you. Submit a story.

\section{Accessibility}




\section{Table of Contents}

Abstract.............................................................................

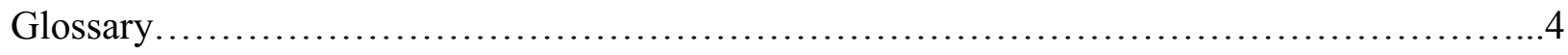

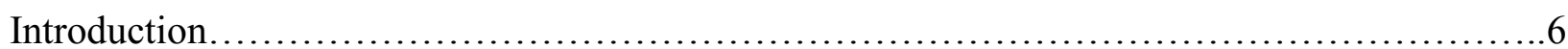

The Challenge of Surgical Procedure Coding.....................................6

Procedure Coding in Resource-Limited Settings...................................8

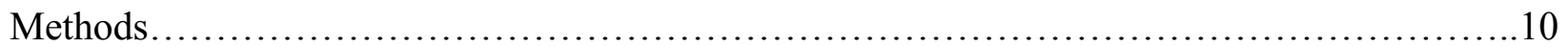

Data Collection............................................................... 10

Data Coding and Analysis....................................................... 11

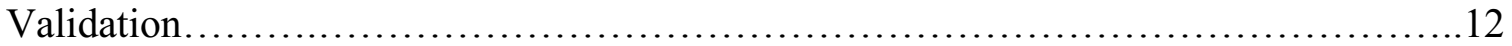

IRB/Ethical Considerations................................................. 13

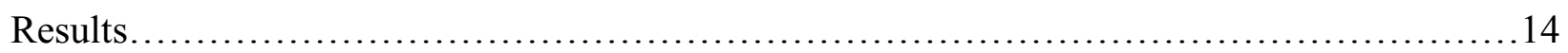

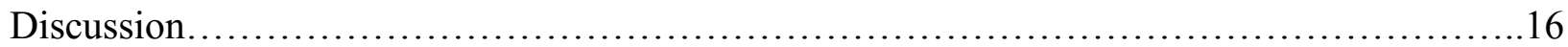

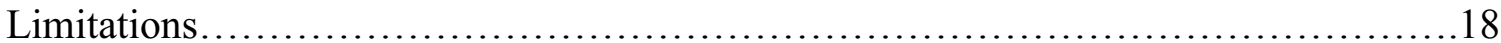

Suggestions for Future Work.............................................19

Conclusion............................................................. 21

Summary..................................................................... 22

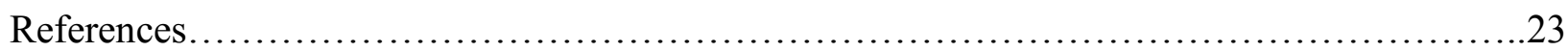

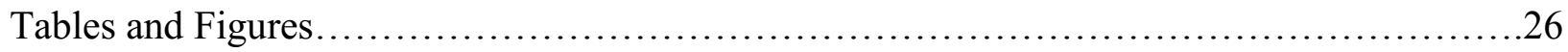

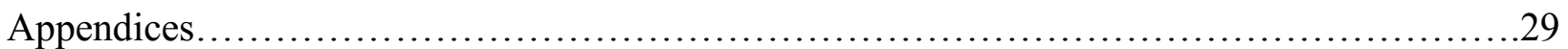




\begin{abstract}
$\underline{\text { Abstract }}$
Conditions amenable to surgery represent a significant portion of the burden of disease worldwide, accounting for $10 \%$ of deaths and $14 \%$ of disability-adjusted life years lost. Today, however, over five billion people worldwide lack access to safe, timely, and affordable surgical care, and the outcomes experienced by surgical patients are least understood in low- and middleincome countries (LMICs).
\end{abstract}

An important barrier to improving access to and quality of surgical care in resource-poor settings is the dearth of reliable data, due in part to the lack of a standardized system for classifying surgical procedures. The applicability of existing procedure coding systems in LMIC hospital settings is limited by their size, complexity, and cost of implementation. The coding of surgical procedures has been a particular challenge in Uganda and at Mbarara Regional Referral Hospital (MRRH), a 323-bed hospital and one of the country's busiest surgical centers. A brief procedure code list could improve data collection for administrative, quality improvement, and research purposes at MRRH and in other resource-limited settings.

Here, we describe the creation and validation of three abbreviated surgical procedure code lists at MRRH. We reviewed operating room logbooks to identify all surgical operations performed between January 1 and December 31, 2014. Based on the documented indication for surgery and procedure(s) performed, we assigned each operation up to four procedure codes from the International Classification of Diseases, 9th Revision, Clinical Modification (ICD-9-CM), Volume 3. These codes were aggregated to generate procedure code lists. Each surgical procedure was assigned codes by one of two investigators working independently, and a random $20 \%$ of procedures were assigned codes by both investigators to evaluate inter-rater reliability.

During the one-year study period, 6464 surgical procedures were performed at MRRH, to which we assigned 435 unique procedure codes. The Kappa statistic representing inter-rater reliability in assignment of codes was 0.7037 .111 procedure codes represented $90 \%$ of codes assigned, 180 represented 95\%, and 278 represented 98\%. These constituted short, intermediate-sized, and long code lists, respectively. 
Finally, to validate these procedure code lists, we assessed the ability of each list to describe surgical procedures performed at MRRH during the two-month validation period of August 1 to September 30, 2015. We found that our short, intermediate-sized, and long lists described 83.2\%, $89.2 \%$, and $92.6 \%$ of procedures performed at MRRH during this time period, respectively.

In conclusion, empirically generated brief procedure code lists based on ICD-9-CM can be used to describe almost all surgical procedures performed at a Ugandan referral hospital. Such a standardized procedure coding system may enable better surgical data collection for research and quality improvement in low-resource setting hospitals. 


\section{Glossary}

MRRH

MUST

LMICs

WHO

CDC

NCHS

AMA

HCUP

NIS

ICD-9

ICD-10

ICD-9-CM

ICD-10-CM

ICD-10-PCS

CPT

ACS

NSQIP

ICPM

ICHI
Mbarara Regional Referral Hospital

Mbarara University of Science and Technology

low- and middle-income countries

World Health Organization

Centers for Disease Control and Prevention

National Center for Health Statistics

American Medical Association

Healthcare Cost and Utilization Project

Nationwide (National) Inpatient Sample

International Classification of Diseases, $9^{\text {th }}$ Revision (WHO) - diagnoses

International Classification of Diseases, $10^{\text {th }}$ Revision (WHO) - diagnoses

International Classification of Diseases, $9^{\text {th }}$ Revision, Clinical Modification (US CDC NCHS) - diagnoses (Volumes 1-2) and procedures (Volume 3)

International Classification of Diseases, $10^{\text {th }}$ Revision, Clinical Modification (US CDC NCHS) - diagnoses

International Classification of Diseases, $10^{\text {th }}$ Revision, Procedure Coding System (US CDC NCHS) - procedures, used for hospital and inpatient billing

Current Procedural Terminology (AMA) - procedures, used for physician and outpatient billing

American College of Surgeons

National Surgical Quality Improvement Program

International Classification of Procedures in Medicine (WHO) - discontinued in $1980 \mathrm{~s}$

International Classification of Health Interventions (WHO) - currently still under development 
$\mathrm{ACHI}$

CCI

OPCS-4

IHTSDO

SNOMED CT
Australian Classification of Health Interventions (Australia)

Canadian Classification of Health Interventions (Canada)

Office of Population Censuses and Surveys Classification of Interventions and Procedures, Version 4 (UK)

International Health Terminology Standards Development Organization

Systematized Nomenclature of Medicine Clinical Terminology (IHTSDO) 


\section{$\underline{\text { Introduction }}$}

Conditions amenable to surgery represent a significant portion of the burden of disease worldwide, ${ }^{1}$ accounting for about $10 \%$ of deaths and $14 \%$ of disability-adjusted life years lost. ${ }^{2}$ The delivery of surgical care is a crucial component of any functioning health care system, given the application of surgery to the prevention, diagnosis, treatment, and palliation of medical disorders in almost every organ system, disease category, and stage of life. ${ }^{3,4}$ Furthermore, essential surgical interventions have been shown to be a cost-effective component of any health system or public health armamentarium, including in resource-poor settings. ${ }^{5,6}$

Today, however, between two and five billion people worldwide lack access to adequate surgical care, and the gap between surgical need and care is greatest in low- and middle-income countries (LMICs). ${ }^{7,8}$ This gap is due to a multitude of factors, including inadequate human resources for health, infrastructure, and essential medicines and supplies. Notably, another important barrier to improving access to and quality of surgical care in resource-poor settings is the dearth of reliable data due to inadequate information collection and reporting systems. The use of unreliable paper records, relatively low investment in information gathering and research from LMIC health systems, and lack of standardization in describing diagnoses and interventions have recently been identified by several major reports as key factors to be addressed in order to expand access to safe, affordable, and timely surgical care. ${ }^{8-13}$

\section{The Challenge of Surgical Procedure Coding}

In particular, one major obstacle to reliable data collection in resource-limited settings is the lack of an internationally standardized classification system for surgical procedures. While the International Classification of Diseases (ICD), maintained by the World Health Organization (WHO) and currently in its $10^{\text {th }}$ iteration (ICD-10), has filled this need for the coding of diagnoses, ${ }^{14}$ a corresponding classification system for procedures does not currently exist. The International Classification of Procedures in Medicine (ICPM) was developed by WHO and first published in 1978, but the rapid expansion and evolution of surgical procedures quickly limited its usefulness, and updates to the ICPM were discontinued in the $1980 \mathrm{~s} .{ }^{15}$ Subsequently, several individual countries, primarily high-income, developed their own systems for classifying 
procedures, including the United States (CPT and ICD-9-CM Volume 3), ${ }^{16}$ Australia (ACHI), ${ }^{17}$ Canada (CCI), ${ }^{18}$ and the United Kingdom (OPCS-4). ${ }^{19}$ International non-governmental organizations have also developed coding systems that encompass procedures, such as the International Health Terminology Standards Development Organization's (IHTSDO) Systematized Nomenclature of Medicine Clinical Terminology (SNOMED CT). ${ }^{20}$ Finally, WHO is currently in the process of developing a successor to ICPM called the International Classification of Health Interventions (ICHI). This system is based on the Australian procedure coding system and is intended for use "in countries that do not, as yet, have their own classification of interventions," but it remains incomplete and the timeline for its completion remains unclear. ${ }^{15}$

The complex nomenclature used to describe the various coding systems in use in the US is worth clarifying here, as these names are often misleading and will be referred to in subsequent portions of this thesis.

Diagnosis Codes: As previously described, ICD-10 is maintained by WHO, used worldwide, and has been used in the US to report causes of mortality on death certificates since 1999. In contrast, ICD-10-CM (Clinical Modification) and its predecessor ICD-9-CM Volumes 1 and 2 are USspecific modifications of ICD-10 (and its predecessor ICD-9) used to classify causes of morbidity for the purposes of clinical documentation and billing. ICD-10-CM is maintained by the National Center for Health Statistics (NCHS) and came into effect on October 1, 2015. It replaced ICD-9-CM Volumes 1 and 2, which had been in use from 1979 to 2015.21

Procedure Codes: ICD-10-PCS (Procedure Coding System) and its predecessor ICD-9-CM Volume 3 are US-specific procedure coding systems. While given the name "ICD," neither is actually based on any international or WHO-maintained procedure coding system (since none exists). ICD-10-PCS is maintained by the NCHS and replaced ICD-9-CM Volume 3 on October 1, 2015. ${ }^{22}$ ICD-10-PCS (and before it, ICD-9-CM Volume 3) is used by hospitals to bill Medicare and private insurers for inpatient procedures, and is also used in surveys administered by the NCHS and large administrative databases such as the Healthcare Cost and Utilization Project (HCUP) Nationwide Inpatient Sample (NIS). ${ }^{23}$ In contrast, CPT (Current Procedural 
Terminology) is another US-specific procedure coding system maintained by the American Medical Association (AMA) and used by physicians and outpatient centers to bill Medicare and private insurers for procedures and other services.${ }^{24} \mathrm{CPT}$ is sometimes also used in certain clinical databases, for example the American College of Surgeons (ACS) National Surgical Quality Improvement Program (NSQIP). ${ }^{25}$

In contrast to the United States, however, LMICs seeking to develop their own classification systems for surgical procedures have often been unable due to limited resources. ${ }^{26}$ For these countries, implementation of existing procedure code systems is also difficult and impractical due to these systems' large size and complexity and limited clinician time and support staff in these settings. The United States' ICD-9-CM Volume 3, for example, contains 3,824 procedure codes, and its replacement ICD-10-PCS contains 71,924 procedure codes. ${ }^{22}$ While this enormous data collection burden is a challenge even in resource-rich settings such as the US, it is outright prohibitive in many LMICs. Reflecting the urgency of this issue, the absence and potential benefits of a coding system for surgical interventions applicable in resource-limited settings were highlighted in the recently published Lancet Commission report Global Surgery 2030. ${ }^{8}$ Other efforts to reduce data collection burden in low-resource settings are underway, such as several studies aiming to develop an efficient risk-adjustment model employing just a few preoperative risk variables to predict mortality and adverse events. ${ }^{27,28}$

\section{Procedure Coding in Resource-Limited Settings}

The classification of surgical procedures has been a particular challenge in Uganda and at Mbarara Regional Referral Hospital (MRRH), a 323-bed public referral hospital located in southwestern Uganda. ${ }^{29}$ Uganda is a nation of 36 million people in East Africa, with a Human Development Index rank of 161 out of 187 nations as determined by the United Nations Development Programme. ${ }^{30}$ Uganda suffers from a severe shortage of human resources for health care, with about one doctor per 8,300 people,$^{31}$ compared to one doctor per 408 people in the United States. ${ }^{32}$ Resources for delivering surgical care in Uganda are also limited, with only one surgeon and 0.2 operating rooms per 100,000 people. ${ }^{33}$ 
MRRH serves a referral population of 4-5 million people, and due to the relatively limited surgical capacity in the health centers and district hospitals in its catchment area, it performs a significant portion of all surgical procedures for the population of southwestern Uganda. To date, however, Uganda and MRRH have had no established system for classifying or coding surgical procedures, making outcomes assessment, quality improvement initiatives, and data reporting to national health authorities difficult to conduct. Specifically, in the absence of procedure codes, it is impossible to describe the case mix at MRRH or other Ugandan hospitals, or to adjust for case mix when assessing quality or comparing outcomes between different hospitals or surgeons. This presented a novel opportunity to empirically develop a concise set of surgical procedure codes based on a review of surgical procedures conducted at MRRH, in order to reduce the data burden prohibiting implementation of such codes in low-resource settings. Here, we present the creation and validation of this procedure code list, which has the potential to improve data collection for administrative, quality improvement, and research purposes at MRRH and in other resourcelimited settings. 


\section{Methods}

\section{Data Collection}

All data collection was conducted in person at MRRH during October and November of 2015. We reviewed all four operating theater (operating room) logbooks (the surgery and anesthesia logbooks from the surgical operating theaters, and the ob/gyn and anesthesia logbooks from the ob/gyn operating theaters) to capture all surgical procedures performed during the period January 1 to December 31, 2014. We reasoned that conducting one full year of data collection would allow for (1) capture of seasonal variations in disease incidence, (2) comparison with existing hospital and Ministry of Health data, and (3) comparison with studies in the existing literature (for example, Walker et al., 2010). ${ }^{34}$ Variables captured included date of operation, procedure performed, diagnosis/indication for surgery (recorded as one data field in the logbooks), patient age, and patient sex. Medical record number and patient name were also captured solely for the purpose of avoiding record duplication. (Patient name was necessary as some logbook entries lacked a patient record number, and also because multiple patients were sometimes mistakenly assigned the same record number.) Data was de-identified by removing patient record numbers and names prior to data coding and analysis.

We manually entered data from the operating theater logbooks into Microsoft Excel. After medical record number and patient name were reviewed to identify and remove duplicate entries (while retaining multiple operations or reoperations on a single patient on different dates), these patient identifiers were replaced by a study ID that was used for all subsequent analysis.

We obtained surgical procedure codes from the 2009 edition of the International Classification of Diseases, $9^{\text {th }}$ Revision, Clinical Modification (ICD-9-CM), Volume 3 - the procedure coding system used by the United States National Center for Health Statistics (NCHS) from 1979 to October 1, 2015. ${ }^{16}$ In the absence of an internationally standardized procedure coding system, ICD-9-CM Volume 3 is one of the most widely used publicly accessible set of English-language procedure codes worldwide, and we thus chose it as the basis of our study. CPT (Common Procedural Terminology) codes, in contrast, are maintained privately by the American Medical Association, and a license must be purchased for their use or reprinting in any product or 
publication. ${ }^{35}$ While ICD-9-CM Volume 3 was replaced in the US by ICD-10-PCS (Procedure Coding System) on October 1, 2015, we chose to use ICD-9-CM procedure codes for three primary reasons. First, the ICD-9-CM procedure codes were fewer in number and thus easier to implement in our study, and the organization of ICD-9-CM codes was also more permissive of accurate code assignment in the context of vague or incompletely specified information (as was the nature of our logbook-derived data). In contrast, ICD-10-PCS codes are far more numerous and specify procedures to a much more granular level, requiring detailed and complete information to achieve accurate code assignment (see Table 1 for examples). Second, we felt that given the more abstract, hexadecimal organization and nomenclature of the ICD-10-PCS codes (as compared to the more intuitive ICD-9-CM codes, illustrated in Table 1), a procedure code list constructed based on ICD-10-PCS codes would be less favorably received and less likely implemented by Ugandan clinicians and hospitals. Finally, almost all currently available US administrative data on surgical procedures use ICD-9-CM rather than ICD-10-PCS codes. We thus felt that basing our code lists on ICD-9-CM codes would allow for more meaningful comparisons between procedures in LMICs coded using our procedure code list and those captured in administrative databases in the US.

\section{Data Coding and Analysis}

After data de-identification, each surgical procedure was reviewed by one of two investigators independently. The background and level of training of the two coders were those of a $4^{\text {th }}$-year American medical student (myself, Charles Liu) and a $2^{\text {nd }}$-year Ugandan general surgery resident (my Ugandan co-investigator, Peter Kayima). Based on the documented indication for surgery and procedure(s) performed, we assigned each operation up to four ICD-9-CM procedure codes. (Multiple procedure codes were needed in some cases, as surgical operations sometimes involved multiple component procedures, such as exploratory laparotomy and sigmoid colectomy, or open reduction of femur fracture and open reduction of humerus fracture.) Each investigator assigned codes to half of all surgical procedures captured during the study period, and a random $20 \%$ of procedures were assigned codes by both investigators.

At the beginning of the data coding process, the two investigators worked together to assign procedure codes to the first 100 surgical procedures, discussing each procedure to reach a 
consensus on the most appropriate code(s) to assign. These initial discussions established the basic rules and principles by which both coders subsequently assigned procedure codes, and also established agreed-on norms for which codes to assign in certain ambiguous but frequently encountered situations (e.g. the vague procedure description "surgical toilet and suturing"). Following the assignment of all procedure codes by both coders, the random $20 \%$ of procedures assigned codes by both investigators was analyzed using Stata 14 to determine inter-rater reliability between the two investigators. We calculated the Cohen's Kappa statistic, as this value goes beyond simple percentage agreement to assess the percentage agreement above and beyond that expected by chance alone. ${ }^{36}$

Following data collection and coding, ICD-9-CM codes assigned were tabulated using Stata 14 in order to determine the frequency with which each procedure was performed during the study period. For the $20 \%$ of procedures coded by both investigators, one investigator's assigned code(s) was chosen at random for each procedure and the other investigator's code(s) discarded for that procedure. The smallest number of ICD-9-CM codes needed to describe at least $90 \%$, $95 \%$, and $98 \%$ (rounded to the nearest percent) of surgical cases performed at MRRH during the study period were identified. These constituted three concise procedure code lists (of differing sizes) applicable to classifying surgical procedures at MRRH and in similar settings. In constructing these three code lists, all procedure codes appearing with equal frequency during the study period were either included or excluded as a group from each code list. In other words, if a given procedure code appeared with frequency " $\mathrm{n}$ " in the study data and was included in a code list, all other codes with frequency "n" would be included in this code list as well, as there would be no basis on which to include some but not all codes appearing with frequency "n."

\section{Validation}

Finally, in order to assess the feasibility and validity of applying the resulting procedure code lists to data collection at MRRH in the future, we conducted a prospective validation analysis. Specifically, we identified all surgical procedures performed at MRRH during August 1 to September 30, 2015, assigned ICD-9-CM codes to these procedures, and determined what percentage of these codes was contained on each of our three procedure code lists. The validation period of August to September 2015 was chosen as it was the most recent two-month period 
fully captured in the MRRH operating theater logbooks at the time of data collection in October 2015. Procedures were captured and coded using the same methodology as described above, with codes assigned by just one investigator (myself). The percentage of assigned codes included in each of the three procedure code lists was determined using Microsoft Excel. We hypothesized that the short (90\%), intermediate-sized (95\%), and long (98\%) procedure code lists would capture greater than or equal to $85 \%, 90 \%$, and $95 \%$ of surgical procedures performed during this two-month validation period, respectively.

\section{IRB/Ethical Considerations}

This research was granted IRB approval by the Partners Human Research Committee (Protocol \#2015P001796). We also secured IRB approval from the Mbarara University of Science and Technology (MUST) Research Ethics Committee, which oversees all research done at MUST and MRRH, and the Uganda National Council for Science and Technology (UNCST), which oversees all human subjects research conducted in the country. Our study involved only retrospective review of medical records (operating theater logbooks) and did not involve any contact with or collection of data from patients. Risk was minimized by de-identifying all data prior to data coding and analysis. 


\section{$\underline{\text { Results }}$}

During the one-year study period, 6464 surgical procedures were performed at MRRH, to which we assigned 7623 total and 435 unique procedure codes. (The total number of codes assigned exceeds the number of procedures as a minority of procedures required multiple codes.) 1288 procedures $(20 \%)$ were chosen randomly to be assigned codes by both investigators independently, and the Kappa statistic representing inter-rater reliability in assignment of codes was 0.7037 , corresponding to "substantial" $(0.60<\kappa \leq 0.80)$ inter-rater reliability. ${ }^{37}$ Furthermore, this represents a conservative estimate of inter-rater reliability, as the two investigators were deemed to be in agreement only when they had assigned the exact same number and combination of codes to a given procedure. (For example, if Coder 1 assigned codes A and B, and Coder 2 assigned codes A, B, and C, the coders were deemed to be in disagreement and no partial agreement was registered.)

As shown in Figure 1, 84\% of surgical procedures were assigned one procedure code, 14\% required two procedure codes, $2 \%$ required three procedure codes, and less than $0.1 \%(\mathrm{n}=17)$ required four procedure codes. As shown in Figure 2, according to the major divisions of ICD-9$\mathrm{CM}$, Volume 3, the procedure types most commonly encountered during calendar year 2014 at MRRH were obstetrical procedures $(49 \%, n=3751)$, operations on the digestive system $(17 \%, n$ $=1285)$, and operations on the female genital organs $(12 \%, \mathrm{n}=932)$. Also common were operations on the nervous system $(5 \%, \mathrm{n}=342)$, operations on the musculoskeletal system $(4 \%$, $\mathrm{n}=336$ ), and operations on the integumentary system, including skin, soft tissue, and breast $(4 \%, n=299)$.

Three code lists were generated by aggregating the most commonly assigned procedure codes. As shown in Table 2, 111 procedure codes represented about $90 \%$ of codes assigned, 180 represented about 95\%, and 278 represented about 98\%. These constituted short, intermediatesized, and long code lists, respectively. Full versions of the code lists can be found in Appendices 1-3, respectively. 
As shown in Figure 3, while relatively few procedure codes (111) were needed to capture 90\% of all procedures performed during the one-year study period, a comparatively large number of procedure codes was needed for each marginal increase in percent capture of procedures -69 additional codes to increase percent capture from $90 \%$ to $95 \%$, 98 codes to increase percent capture from $95 \%$ to $98 \%$, and 157 additional codes to increase percent capture from $98 \%$ to $100 \%$. The full relationship between code list length and percent capture of procedures is shown in Figure 4. As shown in the figure, increasing code list length yields diminishing returns as the percent capture approaches $100 \%$.

Finally, to test and validate these procedure code lists, we assessed the ability of each code list to describe surgical procedures performed at MRRH during the two-month validation period of August 1 to September 30,2015. Specifically, we determined the percent coverage achieved by each code list when applied to the 1665 procedures performed during this period. As shown in Table 2, the short, intermediate, and long procedure code lists described $83.2 \%, 89.2 \%$, and $92.6 \%$ of procedures performed at MRRH during the validation period, respectively. 


\section{$\underline{\text { Discussion }}$}

Here, we describe the creation of a brief procedure code list, based on ICD-9-CM, which may have utility in resource-limited settings. Through our validation, we have also demonstrated that such an empirically generated procedure code list can be used to describe almost all surgical procedures performed at a Ugandan referral hospital.

Such a standardized procedure coding system may enable better surgical data collection in resource-constrained hospitals such as $\mathrm{MRRH}$, and has potential applications in administration, quality improvement, and outcomes research. First, in the area of administration, MRRH and all other public Ugandan hospitals are required to report the number of certain major and minor surgical procedures performed each month to the Uganda Ministry of Health through the online Health Management Information System. ${ }^{38}$ These data are in turn used to track country-level health trends and to inform allocation of resources to public hospitals. A standardized approach to procedure coding might improve the accuracy and detail of this reporting, which in turn could facilitate improved allocation of resources within the Ugandan public hospital system. This is especially important given that Uganda's health care sector has been documented to be underfunded, with inequitable and fragmented financing that exposes patients and their families to impoverishing expenditures. ${ }^{39}$ More broadly, resource allocation in LMICs is often driven by political leverage or incremental budgeting (basing allocations on how resources have always been distributed in the past), ${ }^{40}$ and efforts to move toward needs-based allocation are hindered by inadequate data - a problem these code lists will begin to help address.

To give a specific example of this, Mbarara Regional Referral Hospital has for several years been seeking the designation of National Referral Hospital, based on its clinical volume and subspecialty surgical services offered, but it has thus far been unable to make the case for additional resources. Implementation of standardized procedure codes might lead to better characterization of MRRH's patient volume and procedural complexity, facilitating its designation as a National Referral Hospital if warranted. As MRRH is the busiest of the 14 Ugandan regional referral hospitals by surgical volume, ${ }^{29}$ and as district hospitals perform fewer and less complex surgical procedures, the procedure code lists described in this thesis are likely 
also suitable for use at Uganda's other regional referral and district hospitals. Depending on the extent to which Uganda's National Referral Hospital (Mulago Hospital) performs complex surgeries not seen at MRRH, the lists may also be applicable there.

Second, these surgical procedure code lists have the potential to enable quality improvement (QI) efforts at resource-constrained hospitals in Uganda and beyond, both on an ongoing, day-to-day basis and through more concerted, longer-term QI initiatives. For example, the MRRH surgery department currently does not conduct regularly scheduled morbidity and mortality conferences, and discussion of patient outcomes and how to improve them is hindered by difficulty characterizing the number and types of surgical procedures performed (especially given the large variety of possible procedures). In contrast, for example, the MRRH ob/gyn department more systematically tracks and discusses its maternal mortality events and other bad outcomes, in part because of a national-level focus on lowering maternal mortality, but also because the relatively smaller variety of ob/gyn surgical procedures helps to organize and focus discussions about quality. Implementation of standard procedure codes at hospitals such as MRRH would simplify the complex range of surgical operations performed into a finite and manageable number of procedures for discussion, making it easier to identify operations frequently leading to poor outcomes or associated with marked variation in quality. It would also ensure that comparison of outcomes between hospitals and among clinicians is standardized by comparing outcomes after the same procedure - in other words, by allowing for case mix adjustment. This, in turn, would facilitate the identification and dissemination of best practices.

Third, the procedure code lists described here open the door for more rigorous and impactful surgical outcomes research in resource-limited settings. A basic tenet of outcomes research is risk adjustment, or accounting for different starting levels of risk among patients that may account for observed differences in outcomes (as opposed to true differences in the quality of care provided). An important component of risk adjustment is case mix adjustment, or accounting for patients' diagnoses and (in the case of surgical patients) types of surgical procedures undergone. This adjustment, in turn, is impossible without standardized procedure codes. These code lists thus lay the foundation for case mix- and risk-adjusted outcomes research in resource-constrained settings. Finally, the accurate and thorough identification of relevant 
cases in studies of a particular type or types of operation (e.g. appendectomy, cholecystectomy) is also greatly facilitated by standardized procedure codes.

\section{Limitations}

This study has several limitations. First, as data collection was conducted at only one study site (MRRH), our study was unable to capture geographic variation in surgical procedures performed and, by definition, has limited generalizability beyond MRRH and Uganda. To optimize the generalizability of our results, however, we chose as our study site MRRH, a regional referral hospital with a large catchment population and subspecialty providers, including neurosurgery, orthopedic surgery, plastic surgery, and pediatric surgery. This allowed us to generate procedure code lists that include a broad range of surgical procedures and have potential applicability in a broad range of hospital settings, including district hospitals and regional referral hospitals in Uganda (which perform a comparable or reduced range of surgical procedures compared to MRRH).

Second, since our data was collected only from hospital operating theater logbooks, the quality of our results was dependent on (and limited by) the quality of information recorded in these logbooks, which was sometimes incomplete, missing, or illegible. To address this limitation, we reviewed both the surgical/ob/gyn provider's logbook and the anesthesia provider's logbook for each operating theater, which allowed us to capture information that was missing from one logbook but present in the other. However, this led to an additional subset of cases in which the two logbooks differed in the listed procedure performed. In these cases, we attempted to make a best determination of the correct procedure based on the listed diagnosis, patient age, and patient sex. In cases where these data fields were unhelpful or unavailable, we resolved conflicts in favor of the surgical/ob/gyn provider's logbook, with the reasoning that these providers performed the procedure and were thus more likely to record it correctly than the anesthetic providers. However, as these cases demonstrate, inconsistent data quality is an inherent limitation of this study.

Finally, since our study period was only one calendar year, some rare procedures that are performed at MRRH less frequently than once per year may not have been captured in our study. 
However, the focus of our study was to capture and characterize the most common surgical procedures performed at MRRH, rather than all procedures per se. Furthermore, the procedure code lists generated from the study were created using only the highest frequency $90-98 \%$ of surgical procedures performed, meaning the absence of rare procedures did not affect the codes included in these lists.

\section{Suggestions for Future Work}

The procedure code lists described here suggest several avenues of future work. First, there is opportunity and need for further validation of the procedure code lists, for example by applying the lists to surgical procedures performed at MRRH over a longer timespan than the two-month validation period described here. Perhaps more importantly, the ultimate utility of these code lists in resource-limited settings depends on the ability of clinicians and other providers to apply them efficiently and accurately in the course of routine documentation. This is a significant challenge, given the high ratio of clinical work to providers in these settings and the lack of support staff to assist with coding. It is precisely these human resource limitations, however, that give these lightweight code lists so much potential utility - if they can be implemented. An important form of validation, therefore, will be testing whether the code lists can be adopted and used by surgeons, obstetricians, and anesthetists under the time constraints of patient care. Interrater consistency is also critical to the successful implementation of these code lists - i.e. whether multiple different providers can reliably assign the same codes all or almost all of the time. This would be another important future avenue of inquiry. Closely related to this would be the development of a training curriculum to teach providers how to correctly and reproducibly assign procedure codes, which could be based on existing curricula developed for ICD-9-CM Volume 3.

Going beyond the technical and practical aspects of implementation, an important future step is testing the applicability of these code lists in other, non-Ugandan resource-limited settings. This includes both other LMIC hospitals and resource-constrained hospitals in high-income settings such as the US. Regarding the former, one setting in which suitable data exist is Mozambique, where a collaborative team consisting of surgeons and researchers from the Mozambique Ministry of Health, Universidade Eduardo Mondlane, and the University of California, San 
Diego have collaborated to establish a "NSQIP-Lite" surgical outcomes database based on the ACS NSQIP. ${ }^{41}$ This database captures records of surgical patients from three hospitals in geographically dispersed regions of Mozambique, has been in operation since 2013, and includes fields such as "diagnosis" and "name/type of surgery" that would allow application of the procedure code lists described here. Applying the code lists to data from Mozambique would allow for a true test of the principle that lists developed using single-country data can be broadly utilized in other resource-limited settings. As Dr. John Rose, one of the key leaders of the NSQIP-Lite database team in Mozambique, is currently a surgical resident at Harvard, we hope to be able to reach out and collaborate on this endeavor in the future.

Finally, a third and exciting opportunity for future work lies in using the data collected in this study to compare surgical case mix at MRRH with that at resource-constrained US hospitals, for example those in rural or remote parts of the country. While rural US hospitals are part of the American health care system, they nevertheless face many of the same challenges as LMIC hospitals: resource limitations, geographically disperse patient populations, and competing pressures to treat vs. refer patients with complex surgical pathology. Furthermore, data on the burden of surgically treatable disease are available from both the US and most LMICs, through data sources such as the Institute for Health Metrics and Evaluation (IHME) Global Burden of Disease (GBD) Study (which have already been used to model global surgical need). ${ }^{42}$ Therefore, comparing case mix and case volume at MRRH with that at rural US hospitals, and taking into account differences in the burden of surgical disease in the two locations, might allow us to identify gaps in access to certain surgical procedures in Uganda or the rural US, and provide new perspective on the differences in met surgical need between high- and low-income country settings. Specifically, the HCUP Nationwide Inpatient Sample (NIS) contains data from hundreds of rural US hospitals and utilizes ICD-9-CM procedure codes, ${ }^{23}$ which we have also chosen to use in our study. Using NIS data, we could thus match selected US rural hospitals to MRRH based on number of beds and number of surgical procedures performed per year, allowing comparison of case mix and volume. Since it is possible to interpret the same data as either lack of access to a surgical procedure at one site (e.g. MRRH) with overuse of that same surgical procedure at the other site (e.g. US hospital), we could consider designating a certain country's surgical rate for a given condition as the "ideal" surgical rate. For example, this has 
been done by existing studies in the literature, using surgical rates from New Zealand as the "gold standard" or ideal rate. ${ }^{42}$

\section{Conclusion}

A standard approach to classifying surgical procedures in resource-limited hospitals is critical to improving data collection, resource allocation, and ultimately patient care in these settings. Without a list of procedure codes both comprehensive enough to describe the vast majority of operations performed and concise enough to be feasibly implemented despite time and human resource constraints, quality improvement and outcomes research are severely limited, if not impossible. Rather than attempting to create an entirely new procedure coding system, or choosing which existing codes to include in a code list using expert opinion alone, we chose here to begin with the American ICD-9-CM procedure coding system and to empirically determine which codes appear commonly enough to warrant inclusion in a concise code list. The output of this work, three procedure code lists containing 111, 180, and 278 procedure codes, respectively, lays the foundation for systematic coding of surgical procedures in low-resource settings. With the future directions outlined above and other outgrowths of this work, we hope these code lists will become clinical and research tools used to improve surgical care and quality of life for patients worldwide. 


\section{$\underline{\text { Summary }}$}

There is currently no internationally standardized system for classifying surgical procedures. This poses a major challenge to data gathering in resource-limited settings such as Uganda, since coding systems for surgical procedures developed in high-resource settings are too expensive and impractical to implement given very limited financial resources for health and the lack of support personnel. Here, we describe the creation of a lightweight procedure coding system that could begin to address this gap. By reviewing one year's worth of operating room logbook data at Mbarara Regional Referral Hospital in southwestern Uganda and assigning American procedure codes from a classification system called ICD-9-CM, we were able to generate three short procedure code lists of 111,180 , and 278 codes that describe almost all surgeries performed at this Ugandan hospital. We were then able to test these three code lists on more recent data obtained from the hospital, which confirmed their ability to capture the vast majority of surgeries done. These concise procedure code lists represent a first step toward better characterizing met and unmet surgical need in resource-poor settings, and begin to lay the groundwork for efforts to improve quality of surgical care for patients worldwide. 


\section{$\underline{\text { References }}$}

1. Debas HT, Gosselin R, McCord C, Thind A. Surgery. In: Jamison DT, Breman JG, Measham AR, Alleyne G, Claeson M, Evans DB, et al., editors. Disease Control Priorities in Developing Countries. Washington DC: The International Bank for Reconstruction and Development/The World Bank Group; 2006.

2. Mock CN, Donkor P, Gawande A, Jamison DT, Kruk ME, Debas HT. Essential surgery: key messages from Disease Control Priorities, 3rd edition. Lancet (London, England). 2015;385(9983):2209-19. Epub 2015/02/11. doi: 10.1016/s0140-6736(15)60091-5. PubMed PMID: 25662414.

3. Rose J, Chang DC, Weiser TG, Kassebaum NJ, Bickler SW. The role of surgery in global health: analysis of United States inpatient procedure frequency by condition using the Global Burden of Disease 2010 framework. PloS one. 2014;9(2):e89693. Epub 2014/03/04. doi: 10.1371/journal.pone.0089693. PubMed PMID: 24586967; PubMed Central PMCID: PMCPMC3935922.

4. Meara JG, Hagander L, Leather AJ. Surgery and global health: a Lancet Commission. Lancet (London, England). 2014;383(9911):12-3. Epub 2013/12/18. doi: 10.1016/s01406736(13)62345-4. PubMed PMID: 24332309.

5. Chao TE, Sharma K, Mandigo M, Hagander L, Resch SC, Weiser TG, et al. Costeffectiveness of surgery and its policy implications for global health: a systematic review and analysis. The Lancet Global health. 2014;2(6):e334-45. Epub 2014/08/12. doi: 10.1016/s2214-109x(14)70213-x. PubMed PMID: 25103302.

6. Grimes CE, Henry JA, Maraka J, Mkandawire NC, Cotton M. Cost-effectiveness of surgery in low- and middle-income countries: a systematic review. World journal of surgery. 2014;38(1):252-63. Epub 2013/10/09. doi: 10.1007/s00268-013-2243-y. PubMed PMID: 24101020 .

7. Funk LM, Weiser TG, Berry WR, Lipsitz SR, Merry AF, Enright AC, et al. Global operating theatre distribution and pulse oximetry supply: an estimation from reported data. Lancet (London, England). 2010;376(9746):1055-61. Epub 2010/07/06. doi: 10.1016/s01406736(10)60392-3. PubMed PMID: 20598365.

8. Meara JG, Leather AJ, Hagander L, Alkire BC, Alonso N, Ameh EA, et al. Global Surgery 2030: evidence and solutions for achieving health, welfare, and economic development. Lancet (London, England). 2015;386(9993):569-624. Epub 2015/05/01. doi: 10.1016/s01406736(15)60160-x. PubMed PMID: 25924834.

9. Consultative Expert Working Group on Research and Development. Research and development to meet health needs in developing countries: strengthening global financing and coordination. Geneva, Switzerland: World Health Organization, 2012 April 5.

10. Moran M, Guzman J, Chapman N, Abela-Oversteegen L, Howard R, Farrell P, et al. Neglected Disease Research and Development: The Public Divide. Sydney, Australia: Policy Cures, 2013 December.

11. Rottingen JA, Chamas C. A new deal for global health R\&D? The recommendations of the Consultative Expert Working Group on Research and Development (CEWG). PLoS medicine. 2012;9(5):e1001219. Epub 2012/05/23. doi: 10.1371/journal.pmed.1001219. PubMed PMID: 22615545; PubMed Central PMCID: PMCPMC3352865. 
12. Rottingen JA, Regmi S, Eide M, Young AJ, Viergever RF, Ardal C, et al. Mapping of available health research and development data: what's there, what's missing, and what role is there for a global observatory? Lancet (London, England). 2013;382(9900):1286-307. Epub 2013/05/24. doi: 10.1016/s0140-6736(13)61046-6. PubMed PMID: 23697824.

13. Bickler S, Ozgediz D, Gosselin R, Weiser T, Spiegel D, Hsia R, et al. Key concepts for estimating the burden of surgical conditions and the unmet need for surgical care. World journal of surgery. 2010;34(3):374-80. Epub 2009/10/29. doi: 10.1007/s00268-009-0261-6. PubMed PMID: 19862570; PubMed Central PMCID: PMCPMC2816802.

14. World Health Organization. International Classification of Diseases (ICD) [cited 2016 January]. Available from: http://www.who.int/classifications/icd/en/.

15. World Health Organization. International Classification of Health Interventions (ICHI) [cited 2016 January]. Available from: http://www.who.int/classifications/ichi/en/.

16. Centers for Disease Control and Prevention. International Classification of Diseases, Ninth Revision, Clinical Modification (ICD-9-CM) [updated June 2013; cited 2016 January]. Available from: http://www.cdc.gov/nchs/icd/icd9cm.htm.

17. Australian Consortium for Classification Development. ICD-10-AM/ACHI/ACS [cited 2016 January]. Available from: https://www.accd.net.au/Icd10.aspx.

18. Canadian Institute for Health Information. Canadian Classification of Health Interventions [cited 2016 January]. Available from: https://www.cihi.ca/en/data-andstandards/standards/classification-and-coding/canadian-classification-of-health.

19. Health and Social Care Information Centre. OPCS-4 Classification [cited 2016 January]. Available from: http://systems.hscic.gov.uk/data/clinicalcoding/codingstandards/opcs4.

20. Cornet R, de Keizer N. Forty years of SNOMED: a literature review. BMC medical informatics and decision making. 2008;8 Suppl 1:S2. Epub 2008/11/26. doi: 10.1186/14726947-8-s1-s2. PubMed PMID: 19007439; PubMed Central PMCID: PMCPMC2582789.

21. Centers for Disease Control and Prevention. International Classification of Diseases, Tenth Revision, Clinical Modification (ICD-10-CM) [updated October 2015; cited 2016 January]. Available from: http://www.cdc.gov/nchs/icd/icd10cm.htm.

22. Centers for Disease Control and Prevention. International Classification of Diseases (ICD10-CM/PCS) Transition [updated October 2015; cited 2016 January]. Available from: http://www.cdc.gov/nchs/icd/icd10cm_pcs_background.htm.

23. Healthcare Cost and Utilization Project. Introduction to the HCUP National Inpatient Sample (NIS) 2013: Agency for Healthcare Research and Quality; 2015 [updated November 2015; cited 2016 January]. Available from: https://www.hcupus.ahrq.gov/db/nation/nis/NISIntroduction2013.pdf.

24. Centers for Medicare and Medicaid Services. ICD-9-CM, ICD-10-CM, ICD-10-PCS, CPT, and HCPCS Code Sets [updated May 2015; cited 2016 January]. Available from: https://www.cms.gov/Outreach-and-Education/Medicare-Learning-NetworkMLN/MLNProducts/Downloads/Code-Sets-Text-Only.pdf.

25. American College of Surgeons National Surgical Quality Improvement Program. User Guide for the 2014 ACS NSQIP Participant Use Data File (PUF) 2015 [updated October 2015; cited 2016 January]. Available from: https://www.facs.org/ /media/files/quality\%20programs/nsqip/nsqip_puf_userguide_2014.p df.

26. Paviot BT, Madden R, Moskal L, Zaiss A, Bousquet C, Kumar A, et al. Development of a new international classification of health interventions based on an ontology framework. 
Studies in health technology and informatics. 2011;169:749-53. Epub 2011/09/07. PubMed PMID: 21893847.

27. Anderson JE, Lassiter R, Bickler SW, Talamini MA, Chang DC. Brief tool to measure riskadjusted surgical outcomes in resource-limited hospitals. Archives of surgery (Chicago, Ill : 1960). 2012;147(9):798-803. Epub 2012/09/19. doi: 10.1001/archsurg.2012.699. PubMed PMID: 22987164; PubMed Central PMCID: PMCPMC4282492.

28. Anderson JE, Rose J, Noorbakhsh A, Talamini MA, Finlayson SR, Bickler SW, et al. An efficient risk adjustment model to predict inpatient adverse events after surgery. World journal of surgery. 2014;38(8):1954-60. Epub 2014/03/13. doi: 10.1007/s00268-014-2490-6. PubMed PMID: 24615608.

29. Ministry of Health of Uganda. Annual Health Sector Performance Report 2012-2013. Kampala, Uganda: 2013.

30. United Nations Development Programme. Human Development Report 2013 - The Rise of the South: Human Progress in a Diverse World. New York City: 2013.

31. Central Intelligence Agency. The World Factbook: Uganda [updated January 27, 2016; cited 2016 January]. Available from: https://www.cia.gov/library/publications/the-worldfactbook/geos/ug.html.

32. Central Intelligence Agency. The World Factbook: United States [updated January 5, 2016; cited 2016 January]. Available from: https://www.cia.gov/library/publications/the-worldfactbook/geos/us.html.

33. Linden AF, Sekidde FS, Galukande M, Knowlton LM, Chackungal S, McQueen KA. Challenges of surgery in developing countries: a survey of surgical and anesthesia capacity in Uganda's public hospitals. World journal of surgery. 2012;36(5):1056-65. Epub 2012/03/10. doi: 10.1007/s00268-012-1482-7. PubMed PMID: 22402968.

34. Walker IA, Obua AD, Mouton F, Ttendo S, Wilson IH. Paediatric surgery and anaesthesia in south-western Uganda: a cross-sectional survey. Bulletin of the World Health Organization. 2010;88(12):897-906. Epub 2010/12/03. doi: 10.2471/blt.10.076703. PubMed PMID: 21124714; PubMed Central PMCID: PMCPMC2995189.

35. American Medical Association. CPT Licensing [cited 2016 January]. Available from: http://www.ama-assn.org/ama/pub/physician-resources/solutions-managing-yourpractice/coding-billing-insurance/cpt/cpt-products-services/licensing.page.

36. Cohen J. A coefficient of agreement for nominal scales. Educational and Psychological Measurement. 1960;20(1):37-46.

37. Landis JR, Koch GG. The measurement of observer agreement for categorical data. Biometrics. 1977;33(1):159-74. Epub 1977/03/01. PubMed PMID: 843571.

38. Ministry of Health of Uganda HS, Makerere University School of Public Health,. Uganda Health System Assessment 2011. Kampala, Uganda and Bethesda, MD: 2012 April.

39. Zikusooka CM, Kyomuhang R, Orem JN, Tumwine M. Is health care financing in Uganda equitable? African health sciences. 2009;9 Suppl 2:S52-8. Epub 2010/07/09. PubMed PMID: 20589107; PubMed Central PMCID: PMCPMC2877292.

40. Pearson M. Allocating public resources for health: developing pro-poor approaches. London, UK: Department for International Development (DFID) Health Systems Resource Centre (HSRC), 2002.

41. Quinn JW, Barnard G, Rose J, Greenberg SL, McKone-Sweet K, Meara JG. NSQIP-Lite: Measuring Surgical Outcomes in Mozambique. Lancet Commission on Global Surgery Teaching Cases. 2015. 
42. Rose J, Weiser TG, Hider P, Wilson L, Gruen RL, Bickler SW. Estimated need for surgery worldwide based on prevalence of diseases: a modelling strategy for the WHO Global

Health Estimate. The Lancet Global health. 2015;3 Suppl 2:S13-20. Epub 2015/05/01. doi: 10.1016/s2214-109x(15)70087-2. PubMed PMID: 25926315. 
Tables and Figures

Table 1. Illustrative differences between ICD-9-CM and ICD-10-PCS procedure codes.

\begin{tabular}{|c|c|c|}
\hline $\begin{array}{l}\text { Common } \\
\text { Procedure Name }\end{array}$ & ICD-9-CM Code & Possible ICD-10-PCS Codes \\
\hline Appendectomy & $\begin{array}{l}47.09 \text { Other } \\
\text { appendectomy }\end{array}$ & 0DTJ0ZZ Resection of Appendix, Open Approach \\
\hline Cesarean section & $\begin{array}{l}74.99 \text { Other cesarean } \\
\text { section of unspecified } \\
\text { type }\end{array}$ & $\begin{array}{l}\text { 10D00Z0 Extraction of Products of Conception, Classical, Open Approach } \\
\text { 10D00Z1 Extraction of Products of Conception, Low Cervical, Open Approach } \\
\text { 10D00Z2 Extraction of Products of Conception, Extraperitoneal, Open Approach }\end{array}$ \\
\hline $\begin{array}{l}\text { Open reduction } \\
\text { and internal } \\
\text { fixation of femur }\end{array}$ & $\begin{array}{l}79.35 \text { Open reduction } \\
\text { of fracture with } \\
\text { internal fixation, } \\
\text { femur }\end{array}$ & $\begin{array}{l}\text { 0QS604Z Reposition Right Upper Femur with Internal Fixation Device, Open Approach } \\
\text { 0QS704Z Reposition Left Upper Femur with Internal Fixation Device, Open Approach } \\
\text { 0QS804Z Reposition Right Femoral Shaft with Internal Fixation Device, Open Approach } \\
\text { 0QS904Z Reposition Left Femoral Shaft with Internal Fixation Device, Open Approach } \\
\text { 0QSB04Z Reposition Right Lower Femur with Internal Fixation Device, Open Approach } \\
\text { 0QSC04Z Reposition Left Lower Femur with Internal Fixation Device, Open Approach }\end{array}$ \\
\hline $\begin{array}{l}\text { Wound } \\
\text { debridement }\end{array}$ & $\begin{array}{l}86.28 \text { Nonexcisional } \\
\text { debridement of } \\
\text { wound, infection or } \\
\text { burn }\end{array}$ & $\begin{array}{l}\text { 0JD00ZZ Extraction of Scalp Subcutaneous Tissue and Fascia, Open Approach } \\
\text { 0JD10ZZ Extraction of Face Subcutaneous Tissue and Fascia, Open Approach } \\
\text { 0JD40ZZ Extraction of Anterior Neck Subcutaneous Tissue and Fascia, Open Approach } \\
\text { 0JD50ZZ Extraction of Posterior Neck Subcutaneous Tissue and Fascia, Open Approach } \\
\text { 0JD60ZZ Extraction of Chest Subcutaneous Tissue and Fascia, Open Approach } \\
\text { 0JD70ZZ Extraction of Back Subcutaneous Tissue and Fascia, Open Approach } \\
\text { 0JD80ZZ Extraction of Abdomen Subcutaneous Tissue and Fascia, Open Approach } \\
\text { 0JD90ZZ Extraction of Buttock Subcutaneous Tissue and Fascia, Open Approach } \\
\text { 0JDB0ZZ Extraction of Perineum Subcutaneous Tissue and Fascia, Open Approach } \\
\text { 0JDC0ZZ Extraction of Pelvic Region Subcutaneous Tissue and Fascia, Open Approach } \\
\text { 0JDD0ZZ Extraction of Right Upper Arm Subcutaneous Tissue and Fascia, Open Approach } \\
\text { 0JDF0ZZ Extraction of Left Upper Arm Subcutaneous Tissue and Fascia, Open Approach } \\
\text { 0JDG0ZZ Extraction of Right Lower Arm Subcutaneous Tissue and Fascia, Open Approach } \\
\text { 0JDH0ZZ Extraction of Left Lower Arm Subcutaneous Tissue and Fascia, Open Approach } \\
\text { 0JDJ0ZZ Extraction of Right Hand Subcutaneous Tissue and Fascia, Open Approach } \\
\text { 0JDK0ZZ Extraction of Left Hand Subcutaneous Tissue and Fascia, Open Approach } \\
\text { 0JDL0ZZ Extraction of Right Upper Leg Subcutaneous Tissue and Fascia, Open Approach } \\
\text { 0JDM0ZZ Extraction of Left Upper Leg Subcutaneous Tissue and Fascia, Open Approach } \\
\text { 0JDN0ZZ Extraction of Right Lower Leg Subcutaneous Tissue and Fascia, Open Approach } \\
\text { 0JDP0ZZ Extraction of Left Lower Leg Subcutaneous Tissue and Fascia, Open Approach } \\
\text { 0JDQ0ZZ Extraction of Right Foot Subcutaneous Tissue and Fascia, Open Approach } \\
\text { 0JDR0ZZ Extraction of Left Foot Subcutaneous Tissue and Fascia, Open Approach }\end{array}$ \\
\hline
\end{tabular}

Table 2. Characteristics of the three procedure code lists generated.

\begin{tabular}{|l|l|l|l|l|}
\hline List Name & $\begin{array}{l}\text { Number } \\
\text { of Codes }\end{array}$ & $\begin{array}{l}\text { Frequency } \\
\text { Cutoff for } \\
\text { Code Inclusion }\end{array}$ & $\begin{array}{l}\text { \% of Procedures } \\
\text { Captured in Study } \\
\text { Period (2014) }\end{array}$ & $\begin{array}{l}\text { \% of Procedures } \\
\text { Captured in Prospective } \\
\text { Validation (8-9/2015) }\end{array}$ \\
\hline Short & 111 & $\geq 8$ & $90.0 \%$ & $83.2 \%$ \\
\hline Intermediate & 180 & $\geq 4$ & $94.9 \%$ & $89.2 \%$ \\
\hline Long & 278 & $\geq 2$ & $97.9 \%$ & $92.6 \%$ \\
\hline
\end{tabular}


Figure 1. Number of codes needed to describe each surgical procedure.

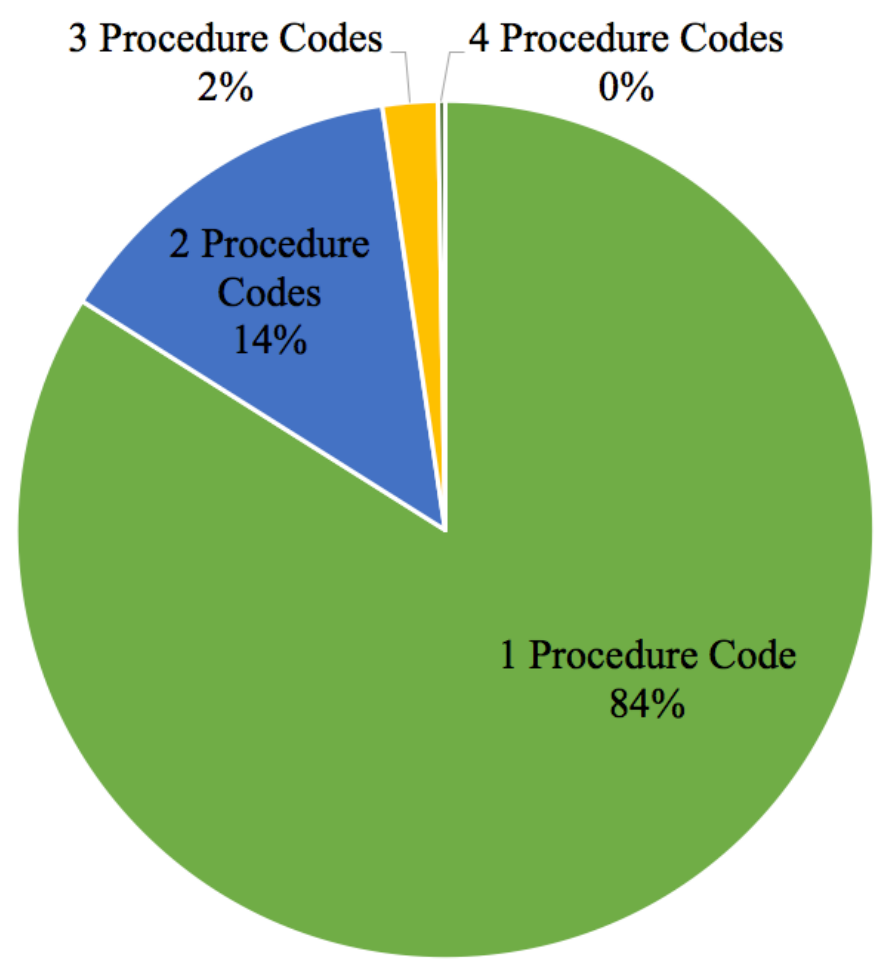

Figure 2. Procedure codes assigned by organ system (major divisions of ICD-9-CM, Volume 3).

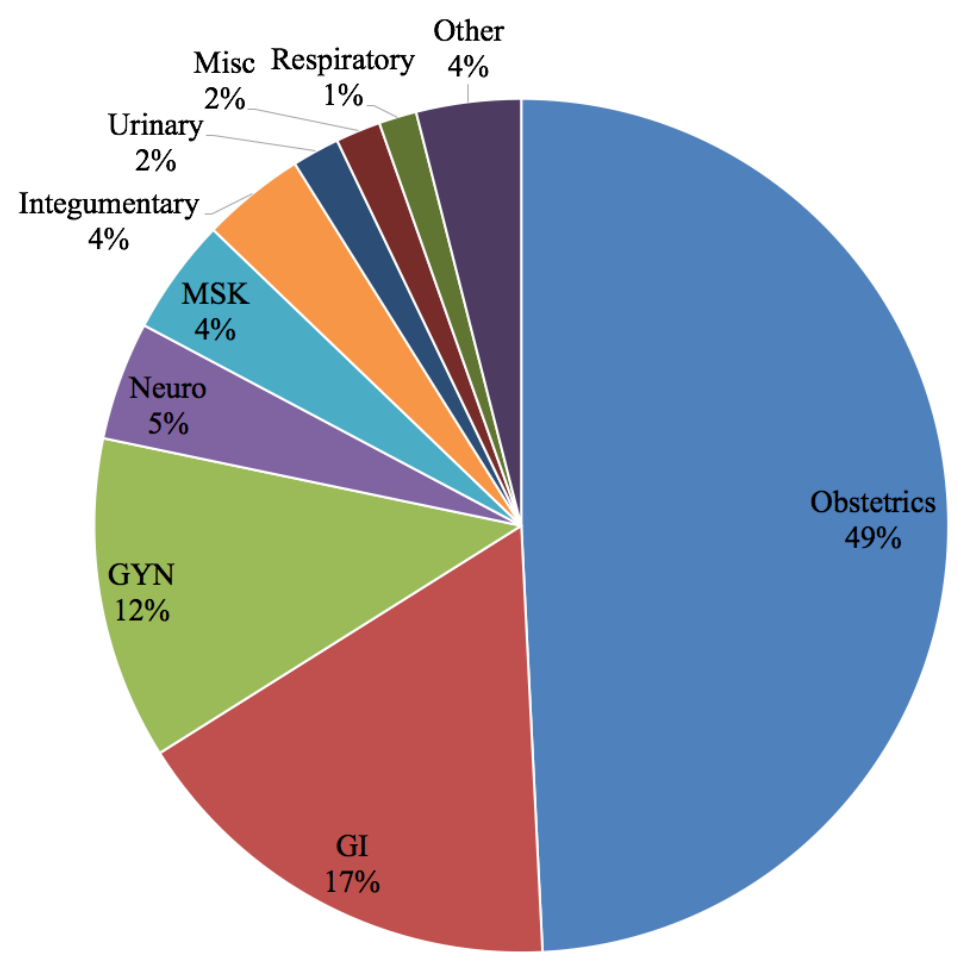


Figure 3. Marginal increase in code list length needed to achieve higher percent capture.

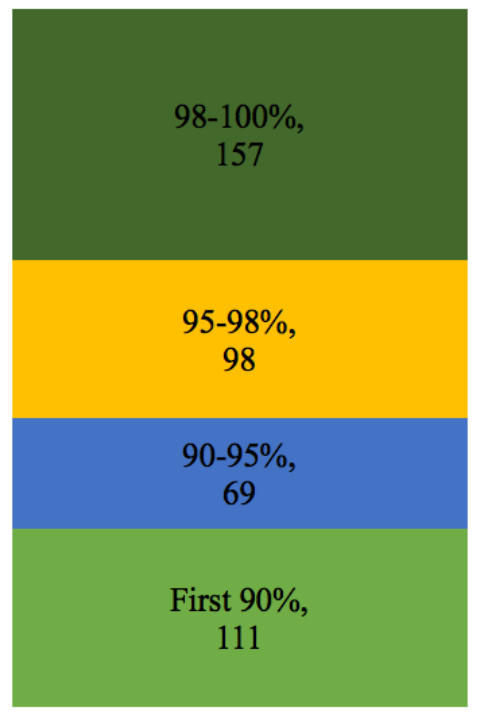

Figure 4. Relationship between code list length and percent capture of procedures.






\section{$\underline{\text { Appendices }}$}

\section{Appendix 1. Short (111-code) surgical procedure code list.}

\begin{tabular}{ll}
\hline Procedure code & Fre \\
\hline 1. OPERATIONS ON THE NERVOUS SYSTEM (01-05) & 136 \\
01.24 Other craniotomy & 13 \\
01.25 Other craniectomy & 82 \\
01.31 Incision of cerebral meninges & 9 \\
02.02 Elevation of skull fracture fragments & 15 \\
02.12 Other repair of cerebral meninges & 23 \\
02.34 Ventricular shunt to abdominal cavity and organs & 27 \\
03.09 Other exploration and decompression of spinal canal & 11 \\
03.52 Repair of spinal myelomeningocele & \\
2. OPERATIONS ON THE ENDOCRINE SYSTEM (06-07) & 8
\end{tabular}

06.4 Complete thyroidectomy

06.7 Excision of thyroglossal duct or tract

5. OPERATIONS ON THE NOSE, MOUTH, AND PHARYNX (21-29)

21.31 Local excision or destruction of intranasal lesion

27.54 Repair of cleft lip

28.2 Tonsillectomy without adenoidectomy

28.3 Tonsillectomy with adenoidectomy

6. OPERATIONS ON THE RESPIRATORY SYSTEM (30-34)

31.1 Temporary tracheostomy

31.42 Laryngoscopy and other tracheoscopy

31.43 Closed [endoscopic] biopsy of larynx

33.22 Fiber-optic bronchoscopy

33.23 Other bronchoscopy

8. OPERATIONS ON THE HEMIC AND LYMPHATIC SYSTEM (40-41)

40.11 Biopsy of lymphatic structure

41.5 Total splenectomy

9. OPERATIONS ON THE DIGESTIVE SYSTEM (42-54)

42.23 Other esophagoscopy

43.19 Other gastrostomy

44.39 Other gastroenterostomy

44.41 Suture of gastric ulcer site

45.62 Other partial resection of small intestine 30

45.73 Open and other right hemicolectomy 13

45.76 Open and other sigmoidectomy 26

45.79 Other and unspecified partial excision of large intestine 16

45.90 Intestinal anastomosis, not otherwise specified 24

45.91 Small-to-small intestinal anastomosis 40

45.93 Other small-to-large intestinal anastomosis 19

46.10 Colostomy, not otherwise specified $\quad 37$

46.20 Ileostomy, not otherwise specified 22

46.51 Closure of stoma of small intestine 9

46.52 Closure of stoma of large intestine 23

46.73 Suture of laceration of small intestine, except duodenum 55

46.80 Intra-abdominal manipulation of intestine, not otherwise specified 13

47.09 Other appendectomy 44

47.2 Drainage of appendiceal abscess 9 
53.00 Unilateral repair of inguinal hernia, not otherwise specified 78

53.49 Other open umbilical herniorrhaphy 17

53.59 Repair of other hernia of anterior abdominal wall 11

54.11 Exploratory laparotomy $\quad 309$

54.12 Reopening of recent laparotomy site $\quad 22$

54.19 Other laparotomy $\quad 52$

54.23 Biopsy of peritoneum 11

54.4 Excision or destruction of peritoneal tissue $\quad 11$

54.59 Other lysis of peritoneal adhesions $\quad 28$

54.61 Reclosure of postoperative disruption of abdominal wall $\quad 42$

54.74 Other repair of omentum 16

10. OPERATIONS ON THE URINARY SYSTEM (55-59)

55.51 Nephroureterectomy

$\begin{array}{ll}57.18 \text { Other suprapubic cystostomy } & 10\end{array}$

57.81 Suture of laceration of bladder 14

57.84 Repair of other fistula of bladder $\quad 37$

11. OPERATIONS ON THE MALE GENITAL ORGANS (60-64)

61.2 Excision of hydrocele (of tunica vaginalis)

62.5 Orchiopexy 15

64.0 Circumcision $\quad 9$

12. OPERATIONS ON THE FEMALE GENITAL ORGANS (65-71)

65.21 Marsupialization of ovarian cyst $\quad 15$

65.29 Other local excision or destruction of ovary 12

65.39 Other unilateral oophorectomy $\quad 39$

65.49 Other unilateral salpingo-oophorectomy $\quad 51$

65.61 Other removal of both ovaries and tubes at same operative episode $\quad 52$

66.39 Other bilateral destruction or occlusion of fallopian tubes $\quad 79$

66.62 Salpingectomy with removal of tubal pregnancy $\quad 68$

67.19 Other diagnostic procedures on cervix $\quad 92$

67.59 Other repair of internal cervical os 10

67.61 Suture of laceration of cervix 11

68.29 Other excision or destruction of lesion of uterus 21

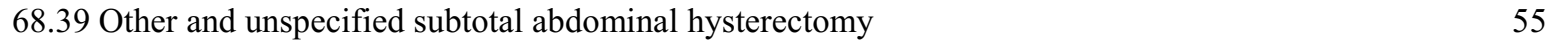

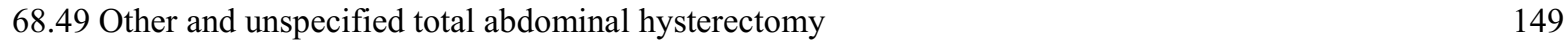

68.59 Other and unspecified vaginal hysterectomy $\quad 44$

68.69 Other and unspecified radical abdominal hysterectomy 14

69.09 Other dilation and curettage $\quad 14$

69.59 Other aspiration curettage of uterus 27

70.29 Other diagnostic procedures on vagina and cul-de-sac 9

70.50 Repair of cystocele and rectocele 12

$\begin{array}{ll}70.51 \text { Repair of cystocele } & 30\end{array}$

70.73 Repair of rectovaginal fistula 13

70.77 Vaginal suspension and fixation $\quad 29$

$\begin{array}{ll}71.23 \text { Marsupialization of Bartholin's gland (cyst) } & 11\end{array}$

13. OBSTETRICAL PROCEDURES (72-75)

74.3 Removal of extratubal ectopic pregnancy 8

74.99 Other cesarean section of unspecified type $\quad 3597$

75.4 Manual removal of retained placenta 17

$\begin{array}{ll}75.51 \text { Repair of current obstetric laceration of cervix } & 10\end{array}$

75.52 Repair of current obstetric laceration of corpus uteri 9

75.62 Repair of current obstetric laceration of rectum and sphincter ani $\quad 52$ 
75.69 Repair of other current obstetric laceration

14. OPERATIONS ON THE MUSCULOSKELETAL SYSTEM (76-84)

77.07 Sequestrectomy, tibia and fibula

79.06 Closed reduction of fracture without internal fixation, tibia and fibula

79.35 Open reduction of fracture with internal fixation, femur

79.66 Debridement of open fracture site, tibia and fibula

81.05 Dorsal and dorsolumbar fusion, posterior technique

81.52 Partial hip replacement

83.09 Other incision of soft tissue 11

$\begin{array}{ll}83.21 \text { Biopsy of soft tissue } & 14\end{array}$

83.49 Other excision of soft tissue 18

84.17 Amputation above knee $\quad 15$

15. OPERATIONS ON THE INTEGUMENTARY SYSTEM (85-86)

85.21 Local excision of lesion of breast $\quad 10$

85.41 Unilateral simple mastectomy 12

86.04 Other incision with drainage of skin and subcutaneous tissue 73

86.22 Excisional debridement of wound, infection, or burn 54

86.28 Nonexcisional debridement of wound, infection or burn 47

86.3 Other local excision or destruction of lesion or tissue of skin and subcutaneous tissue 17

86.59 Closure of skin and subcutaneous tissue of other sites 57

86.60 Free skin graft, not otherwise specified 12

16. MISCELLANEOUS DIAGNOSTIC AND THERAPEUTIC PROCEDURES (87-99)

89.26 Gynecological examination

98.02 Removal of intraluminal foreign body from esophagus without incision 31

98.11 Removal of intraluminal foreign body from ear without incision 13

98.15 Removal of intraluminal foreign body from trachea and bronchus without incision 31 


\section{Appendix 2. Intermediate-sized (180-code) surgical procedure code list.}

\begin{tabular}{|c|c|}
\hline Procedure code & Frequency \\
\hline \multicolumn{2}{|l|}{ 1. OPERATIONS ON THE NERVOUS SYSTEM (01-05) } \\
\hline 01.24 Other craniotomy & 136 \\
\hline 01.25 Other craniectomy & 13 \\
\hline 01.31 Incision of cerebral meninges & 82 \\
\hline 01.59 Other excision or destruction of lesion or tissue of brain & 6 \\
\hline 02.02 Elevation of skull fracture fragments & 9 \\
\hline 02.12 Other repair of cerebral meninges & 15 \\
\hline 02.2 Ventriculostomy & 6 \\
\hline 02.34 Ventricular shunt to abdominal cavity and organs & 23 \\
\hline 03.09 Other exploration and decompression of spinal canal & 27 \\
\hline 03.51 Repair of spinal meningocele & 4 \\
\hline 03.52 Repair of spinal myelomeningocele & 11 \\
\hline \multicolumn{2}{|l|}{ 2. OPERATIONS ON THE ENDOCRINE SYSTEM (06-07) } \\
\hline 06.39 Other partial thyroidectomy & 5 \\
\hline 06.4 Complete thyroidectomy & 8 \\
\hline 06.7 Excision of thyroglossal duct or tract & 8 \\
\hline \multicolumn{2}{|l|}{ 4. OPERATIONS ON THE EAR (18-20) } \\
\hline 18.21 Excision of preauricular sinus & 7 \\
\hline 18.29 Excision or destruction of other lesion of external ear & 7 \\
\hline 19.4 Myringoplasty & 4 \\
\hline 20.51 Excision of lesion of middle ear & 4 \\
\hline \multicolumn{2}{|c|}{ 5. OPERATIONS ON THE NOSE, MOUTH, AND PHARYNX (21-29) } \\
\hline 21.31 Local excision or destruction of intranasal lesion & 9 \\
\hline 27.54 Repair of cleft lip & 10 \\
\hline 28.0 Incision and drainage of tonsil and peritonsillar structures & 6 \\
\hline 28.2 Tonsillectomy without adenoidectomy & 8 \\
\hline 28.3 Tonsillectomy with adenoidectomy & 20 \\
\hline 29.11 Pharyngoscopy & 7 \\
\hline 29.12 Pharyngeal biopsy & 5 \\
\hline \multicolumn{2}{|l|}{ 6. OPERATIONS ON THE RESPIRATORY SYSTEM (30-34) } \\
\hline 31.1 Temporary tracheostomy & 13 \\
\hline 31.42 Laryngoscopy and other tracheoscopy & 26 \\
\hline 31.43 Closed [endoscopic] biopsy of larynx & 10 \\
\hline 33.22 Fiber-optic bronchoscopy & 10 \\
\hline 33.23 Other bronchoscopy & 31 \\
\hline 34.02 Exploratory thoracotomy & 7 \\
\hline 34.04 Insertion of intercostal catheter for drainage & 6 \\
\hline \multicolumn{2}{|c|}{ 8. OPERATIONS ON THE HEMIC AND LYMPHATIC SYSTEM (40-41) } \\
\hline 40.11 Biopsy of lymphatic structure & 23 \\
\hline 40.21 Excision of deep cervical lymph node & 7 \\
\hline 41.5 Total splenectomy & 37 \\
\hline \multicolumn{2}{|l|}{ 9. OPERATIONS ON THE DIGESTIVE SYSTEM (42-54) } \\
\hline 42.23 Other esophagoscopy & 21 \\
\hline 43.19 Other gastrostomy & 38 \\
\hline 44.15 Open biopsy of stomach & 5 \\
\hline 44.39 Other gastroenterostomy & 24 \\
\hline 44.41 Suture of gastric ulcer site & 24 \\
\hline 45.62 Other partial resection of small intestine & 30 \\
\hline 45.73 Open and other right hemicolectomy & 13 \\
\hline
\end{tabular}


45.76 Open and other sigmoidectomy 26

45.79 Other and unspecified partial excision of large intestine 16

45.90 Intestinal anastomosis, not otherwise specified $\quad 24$

$\begin{array}{ll}45.91 \text { Small-to-small intestinal anastomosis } & 40\end{array}$

45.93 Other small-to-large intestinal anastomosis $\quad 19$

45.94 Large-to-large intestinal anastomosis $\quad 6$

46.01 Exteriorization of small intestine $\quad 5$

$\begin{array}{ll}46.03 \text { Exteriorization of large intestine } & 6\end{array}$

46.10 Colostomy, not otherwise specified $\quad 37$

46.20 Ileostomy, not otherwise specified $\quad 22$

46.21 Temporary ileostomy $\quad 4$

46.39 Other enterostomy $\quad 4$

46.51 Closure of stoma of small intestine 9

46.52 Closure of stoma of large intestine 23

46.73 Suture of laceration of small intestine, except duodenum $\quad 55$

46.80 Intra-abdominal manipulation of intestine, not otherwise specified 13

46.81 Intra-abdominal manipulation of small intestine 5

47.09 Other appendectomy $\quad 44$

47.2 Drainage of appendiceal abscess $\quad 9$

48.25 Open biopsy of rectum $\quad 5$

48.79 Other repair of rectum $\quad 7$

49.29 Other diagnostic procedures on anus and perianal tissue $\quad 5$

49.79 Other repair of anal sphincter $\quad 6$

50.12 Open biopsy of liver $\quad 6$

50.61 Closure of laceration of liver $\quad 6$

51.22 Cholecystectomy 19

51.32 Anastomosis of gallbladder to intestine 6

$\begin{array}{ll}53.00 \text { Unilateral repair of inguinal hernia, not otherwise specified } & 78\end{array}$

53.49 Other open umbilical herniorrhaphy 17

53.59 Repair of other hernia of anterior abdominal wall 11

$\begin{array}{ll}53.9 \text { Other hernia repair } & 7\end{array}$

54.0 Incision of abdominal wall $\quad 6$

54.11 Exploratory laparotomy $\quad 309$

54.12 Reopening of recent laparotomy site $\quad 22$

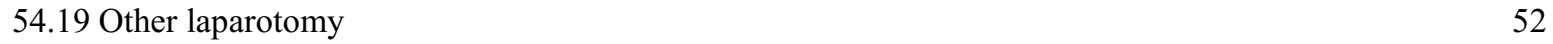

54.23 Biopsy of peritoneum 11

54.29 Other diagnostic procedures on abdominal region $\quad 4$

54.4 Excision or destruction of peritoneal tissue 11

54.59 Other lysis of peritoneal adhesions 28

54.61 Reclosure of postoperative disruption of abdominal wall $\quad 42$

54.71 Repair of gastroschisis $\quad 6$

54.72 Other repair of abdominal wall $\quad 4$

54.74 Other repair of omentum 16

10. OPERATIONS ON THE URINARY SYSTEM (55-59)
55.51 Nephroureterectomy

$\begin{array}{ll}57.18 \text { Other suprapubic cystostomy } & 10\end{array}$

57.41 Transurethral lysis of intraluminal adhesions $\quad 5$

57.81 Suture of laceration of bladder $\quad 14$

57.84 Repair of other fistula of bladder $\quad 37$

58.29 Other diagnostic procedures on urethra and periurethral tissue $\quad 4$

58.43 Closure of other fistula of urethra $\quad 5$

$\begin{array}{ll}58.45 \text { Repair of hypospadias or epispadias } & 7\end{array}$ 
58.46 Other reconstruction of urethra

58.49 Other repair of urethra

11. OPERATIONS ON THE MALE GENITAL ORGANS (60-64)

61.2 Excision of hydrocele (of tunica vaginalis)

62.3 Unilateral orchiectomy

62.5 Orchiopexy

64.0 Circumcision

12. OPERATIONS ON THE FEMALE GENITAL ORGANS (65-71)

65.21 Marsupialization of ovarian cyst

65.29 Other local excision or destruction of ovary

65.39 Other unilateral oophorectomy

65.49 Other unilateral salpingo-oophorectomy

65.61 Other removal of both ovaries and tubes at same operative episode 52

66.39 Other bilateral destruction or occlusion of fallopian tubes 79

66.62 Salpingectomy with removal of tubal pregnancy 68

67.19 Other diagnostic procedures on cervix 92

67.39 Other excision or destruction of lesion or tissue of cervix 4

$\begin{array}{ll}67.59 \text { Other repair of internal cervical os } & 10\end{array}$

67.61 Suture of laceration of cervix 11

68.29 Other excision or destruction of lesion of uterus 21

68.39 Other and unspecified subtotal abdominal hysterectomy

68.49 Other and unspecified total abdominal hysterectomy 149

68.59 Other and unspecified vaginal hysterectomy 44

68.69 Other and unspecified radical abdominal hysterectomy 14

68.9 Other and unspecified hysterectomy 6

69.02 Dilation and curettage following delivery or abortion 7

69.09 Other dilation and curettage $\quad 14$

69.41 Suture of laceration of uterus 5

69.59 Other aspiration curettage of uterus $\quad 27$

70.29 Other diagnostic procedures on vagina and cul-de-sac 9

70.50 Repair of cystocele and rectocele $\quad 12$

$\begin{array}{ll}70.51 \text { Repair of cystocele } & 30\end{array}$

70.73 Repair of rectovaginal fistula $\quad 13$

\begin{tabular}{l}
70.77 Vaginal suspension and fixation \\
\hline 71.11 Biopsy
\end{tabular}

71.11 Biopsy of vulva 5

71.23 Marsupialization of Bartholin's gland (cyst) 11

71.3 Other local excision or destruction of vulva and perineum 7

71.71 Suture of laceration of vulva or perineum 4

71.79 Other repair of vulva and perineum 4

13. OBSTETRICAL PROCEDURES (72-75)

74.3 Removal of extratubal ectopic pregnancy

74.99 Other cesarean section of unspecified type

75.4 Manual removal of retained placenta 17

$\begin{array}{ll}75.51 \text { Repair of current obstetric laceration of cervix } & 10\end{array}$

$\begin{array}{ll}75.52 \text { Repair of current obstetric laceration of corpus uteri } & 9\end{array}$

75.61 Repair of current obstetric laceration of bladder and urethra 4

75.62 Repair of current obstetric laceration of rectum and sphincter ani 52

75.69 Repair of other current obstetric laceration 44

14. OPERATIONS ON THE MUSCULOSKELETAL SYSTEM (76-84)

77.00 Sequestrectomy, unspecified site

77.05 Sequestrectomy, femur

5

77.07 Sequestrectomy, tibia and fibula 
78.15 Application of external fixator device, femur

79.02 Closed reduction of fracture without internal fixation, radius and ulna 4

79.06 Closed reduction of fracture without internal fixation, tibia and fibula 12

79.31 Open reduction of fracture with internal fixation, humerus 7

79.35 Open reduction of fracture with internal fixation, femur 40

79.36 Open reduction of fracture with internal fixation, tibia and fibula 6

79.39 Open reduction of fracture with internal fixation, other specified bone 5

79.65 Debridement of open fracture site, femur 4

79.66 Debridement of open fracture site, tibia and fibula 12

80.16 Other arthrotomy, knee 5

81.05 Dorsal and dorsolumbar fusion, posterior technique 17

81.52 Partial hip replacement 8

82.45 Other suture of other tendon of hand 4

83.09 Other incision of soft tissue 11

83.14 Fasciotomy

$\begin{array}{ll}83.21 \text { Biopsy of soft tissue } & 14\end{array}$

83.39 Excision of lesion of other soft tissue 5

$\begin{array}{ll}83.49 \text { Other excision of soft tissue } & 18\end{array}$

83.64 Other suture of tendon 6

84.01 Amputation and disarticulation of finger 4

84.15 Other amputation below knee 6

84.17 Amputation above knee $\quad 15$

84.3 Revision of amputation stump 6

15. OPERATIONS ON THE INTEGUMENTARY SYSTEM (85-86)

85.21 Local excision of lesion of breast $\quad 10$

85.41 Unilateral simple mastectomy 12

86.04 Other incision with drainage of skin and subcutaneous tissue 73

86.22 Excisional debridement of wound, infection, or burn 54

86.28 Nonexcisional debridement of wound, infection or burn 47

86.3 Other local excision or destruction of lesion or tissue of skin and subcutaneous tissue 17

86.59 Closure of skin and subcutaneous tissue of other sites 57

86.60 Free skin graft, not otherwise specified 12

16. MISCELLANEOUS DIAGNOSTIC AND THERAPEUTIC PROCEDURES (87-99)

89.26 Gynecological examination

11

93.51 Application of plaster jacket $\quad 7$

93.54 Application of splint

93.57 Application of other wound dressing 4

98.02 Removal of intraluminal foreign body from esophagus without incision 31

98.11 Removal of intraluminal foreign body from ear without incision 13

98.13 Removal of intraluminal foreign body from pharynx without incision 7

98.15 Removal of intraluminal foreign body from trachea and bronchus without incision 31 


\section{Appendix 3. Long (278-code) surgical procedure code list.}

\begin{tabular}{|c|c|}
\hline Procedure code & Frequency \\
\hline \multicolumn{2}{|l|}{ 1. OPERATIONS ON THE NERVOUS SYSTEM (01-05) } \\
\hline 01.14 Open biopsy of brain & 2 \\
\hline 01.24 Other craniotomy & 136 \\
\hline 01.25 Other craniectomy & 13 \\
\hline 01.31 Incision of cerebral meninges & 82 \\
\hline 01.39 Other incision of brain & 2 \\
\hline 01.59 Other excision or destruction of lesion or tissue of brain & 6 \\
\hline 02.02 Elevation of skull fracture fragments & 9 \\
\hline 02.12 Other repair of cerebral meninges & 15 \\
\hline 02.2 Ventriculostomy & 6 \\
\hline 02.34 Ventricular shunt to abdominal cavity and organs & 23 \\
\hline 03.09 Other exploration and decompression of spinal canal & 27 \\
\hline 03.51 Repair of spinal meningocele & 4 \\
\hline 03.52 Repair of spinal myelomeningocele & 11 \\
\hline 03.53 Repair of vertebral fracture & 3 \\
\hline \multicolumn{2}{|l|}{ 2. OPERATIONS ON THE ENDOCRINE SYSTEM (06-07) } \\
\hline 06.2 Unilateral thyroid lobectomy & 3 \\
\hline 06.39 Other partial thyroidectomy & 5 \\
\hline 06.4 Complete thyroidectomy & 8 \\
\hline 06.7 Excision of thyroglossal duct or tract & 8 \\
\hline 07.63 Partial excision of pituitary gland, unspecified approach & 3 \\
\hline \multicolumn{2}{|l|}{ 3. OPERATIONS ON THE EYE (08-16) } \\
\hline 11.51 Suture of corneal laceration & 2 \\
\hline \multicolumn{2}{|l|}{ 4. OPERATIONS ON THE EAR (18-20) } \\
\hline 18.09 Other incision of external ear & 3 \\
\hline 18.21 Excision of preauricular sinus & 7 \\
\hline 18.29 Excision or destruction of other lesion of external ear & 7 \\
\hline 19.4 Myringoplasty & 4 \\
\hline 20.01 Myringotomy with insertion of tube & 3 \\
\hline 20.21 Incision of mastoid & 2 \\
\hline 20.49 Other mastoidectomy & 3 \\
\hline 20.51 Excision of lesion of middle ear & 4 \\
\hline \multicolumn{2}{|c|}{ 5. OPERATIONS ON THE NOSE, MOUTH, AND PHARYNX (21-29) } \\
\hline 21.31 Local excision or destruction of intranasal lesion & 9 \\
\hline 22.19 Other diagnostic procedures on nasal sinuses & 3 \\
\hline 22.2 Intranasal antrotomy & 2 \\
\hline 22.39 Other external maxillary antrotomy & 2 \\
\hline 22.63 Ethmoidectomy & 2 \\
\hline 25.51 Suture of laceration of tongue & 2 \\
\hline 26.29 Other excision of salivary gland lesion & 3 \\
\hline 26.32 Complete sialoadenectomy & 3 \\
\hline 27.54 Repair of cleft lip & 10 \\
\hline 27.62 Correction of cleft palate & 2 \\
\hline 28.0 Incision and drainage of tonsil and peritonsillar structures & 6 \\
\hline 28.2 Tonsillectomy without adenoidectomy & 8 \\
\hline 28.3 Tonsillectomy with adenoidectomy & 20 \\
\hline 28.6 Adenoidectomy without tonsillectomy & 2 \\
\hline 29.11 Pharyngoscopy & 7 \\
\hline 29.12 Pharyngeal biopsy & 5 \\
\hline
\end{tabular}




\section{OPERATIONS ON THE RESPIRATORY SYSTEM (30-34)}

31.1 Temporary tracheostomy

31.42 Laryngoscopy and other tracheoscopy 26

31.43 Closed [endoscopic] biopsy of larynx 10

$\begin{array}{ll}33.22 \text { Fiber-optic bronchoscopy } & 10\end{array}$

33.23 Other bronchoscopy

$\begin{array}{ll}34.02 \text { Exploratory thoracotomy } & 7\end{array}$

$\begin{array}{ll}34.04 \text { Insertion of intercostal catheter for drainage } & 6\end{array}$

34.82 Suture of laceration of diaphragm

8. OPERATIONS ON THE HEMIC AND LYMPHATIC SYSTEM (40-41)

40.11 Biopsy of lymphatic structure

40.21 Excision of deep cervical lymph node $\quad 7$

40.3 Regional lymph node excision 2

41.33 Open biopsy of spleen $\quad 2$

41.5 Total splenectomy

9. OPERATIONS ON THE DIGESTIVE SYSTEM (42-54)

42.23 Other esophagoscopy

43.19 Other gastrostomy

43.3 Pyloromyotomy

43.7 Partial gastrectomy with anastomosis to jejunum

44.15 Open biopsy of stomach

44.39 Other gastroenterostomy

44.41 Suture of gastric ulcer site

44.42 Suture of duodenal ulcer site

44.61 Suture of laceration of stomach

45.00 Incision of intestine, not otherwise specified

45.26 Open biopsy of large intestine

45.62 Other partial resection of small intestine

45.73 Open and other right hemicolectomy

45.75 Open and other left hemicolectomy

(1)

45.79 Other and unspecified partial excision of large intestine 16

45.90 Intestinal anastomosis, not otherwise specified 24

45.91 Small-to-small intestinal anastomosis 40

45.93 Other small-to-large intestinal anastomosis 19

45.94 Large-to-large intestinal anastomosis 6

46.01 Exteriorization of small intestine 5

46.03 Exteriorization of large intestine 6

46.10 Colostomy, not otherwise specified $\quad 37$

46.11 Temporary colostomy 2

46.20 Ileostomy, not otherwise specified 22

46.21 Temporary ileostomy 4

46.39 Other enterostomy 4

46.51 Closure of stoma of small intestine 9

46.52 Closure of stoma of large intestine 23

46.73 Suture of laceration of small intestine, except duodenum 55

46.74 Closure of fistula of small intestine, except duodenum 3

46.75 Suture of laceration of large intestine 2

46.80 Intra-abdominal manipulation of intestine, not otherwise specified 13

46.81 Intra-abdominal manipulation of small intestine 5

46.93 Revision of anastomosis of small intestine 3

47.09 Other appendectomy 44 
47.2 Drainage of appendiceal abscess

48.24 Closed [endoscopic] biopsy of rectum 2

48.25 Open biopsy of rectum

48.29 Other diagnostic procedures on rectum, rectosigmoid and perirectal tissue

48.40 Pull-through resection of rectum, not otherwise specified 2

48.69 Other resection of rectum 2

48.71 Suture of laceration of rectum 3

$\begin{array}{ll}48.79 \text { Other repair of rectum } & 7\end{array}$

49.29 Other diagnostic procedures on anus and perianal tissue $\quad 5$

49.46 Excision of hemorrhoids $\quad 3$

$\begin{array}{ll}49.79 \text { Other repair of anal sphincter } & 6\end{array}$

49.99 Other operations on anus 2

50.0 Hepatotomy $\quad 2$

50.12 Open biopsy of liver $\quad 6$

50.61 Closure of laceration of liver $\quad 6$

$\begin{array}{ll}51.22 \text { Cholecystectomy } & 19\end{array}$

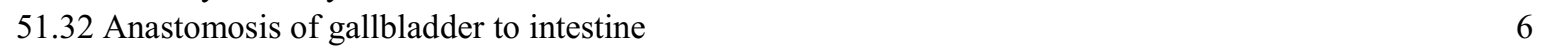

51.36 Choledochoenterostomy 2

51.43 Insertion of choledochohepatic tube for decompression $\quad 2$

52.12 Open biopsy of pancreas 3

53.00 Unilateral repair of inguinal hernia, not otherwise specified $\quad 78$

53.02 Other and open repair of indirect inguinal hernia 2

53.29 Other unilateral femoral herniorrhaphy 2

53.49 Other open umbilical herniorrhaphy 17

53.59 Repair of other hernia of anterior abdominal wall 11

53.61 Other open incisional hernia repair with graft or prosthesis 2

$\begin{array}{ll}53.9 \text { Other hernia repair } & 7\end{array}$

54.0 Incision of abdominal wall $\quad 6$

54.11 Exploratory laparotomy $\quad 309$

54.12 Reopening of recent laparotomy site $\quad 22$

54.19 Other laparotomy $\quad 52$

54.23 Biopsy of peritoneum 11

54.29 Other diagnostic procedures on abdominal region 4

54.4 Excision or destruction of peritoneal tissue 11

54.59 Other lysis of peritoneal adhesions 28

54.61 Reclosure of postoperative disruption of abdominal wall $\quad 42$

54.71 Repair of gastroschisis $\quad 6$

54.72 Other repair of abdominal wall $\quad 4$

54.74 Other repair of omentum 16

10. OPERATIONS ON THE URINARY SYSTEM (55-59)
55.24 Open biopsy of kidney

55.51 Nephroureterectomy 13

56.74 Ureteroneocystostomy $\quad 3$

$\begin{array}{ll}57.18 \text { Other suprapubic cystostomy } & 10\end{array}$

57.32 Other cystoscopy 2

57.41 Transurethral lysis of intraluminal adhesions $\quad 5$

57.81 Suture of laceration of bladder $\quad 14$

$\begin{array}{ll}57.84 \text { Repair of other fistula of bladder } & 37\end{array}$

57.89 Other repair of bladder $\quad 3$

57.94 Insertion of indwelling urinary catheter 2

58.1 Urethral meatotomy $\quad 2$

58.29 Other diagnostic procedures on urethra and periurethral tissue $\quad 4$ 
58.43 Closure of other fistula of urethra

58.45 Repair of hypospadias or epispadias

58.46 Other reconstruction of urethra

58.47 Urethral meatoplasty

58.49 Other repair of urethra

11. OPERATIONS ON THE MALE GENITAL ORGANS (60-64)

61.0 Incision and drainage of scrotum and tunica vaginalis

61.2 Excision of hydrocele (of tunica vaginalis)

62.3 Unilateral orchiectomy

62.41 Removal of both testes at same operative episode

62.5 Orchiopexy

63.73 Vasectomy

64.0 Circumcision

12. OPERATIONS ON THE FEMALE GENITAL ORGANS (65-71)

65.21 Marsupialization of ovarian cyst

65.29 Other local excision or destruction of ovary

65.39 Other unilateral oophorectomy

65.49 Other unilateral salpingo-oophorectomy

65.61 Other removal of both ovaries and tubes at same operative episode

66.39 Other bilateral destruction or occlusion of fallopian tubes

66.62 Salpingectomy with removal of tubal pregnancy

67.12 Other cervical biopsy

67.19 Other diagnostic procedures on cervix

67.39 Other excision or destruction of lesion or tissue of cervix

67.61 Suture of laceration of cervix

68.21 Division of endometrial synechiae

68.29 Other excision or destruction of lesion of uterus

68.39 Other and unspecified subtotal abdominal hysterectomy

68.49 Other and unspecified total abdominal hysterectomy

68.59 Other and unspecified vaginal hysterectomy

68.69 Other and unspecified radical abdominal hysterectomy

68.9 Other and unspecified hysterectomy

69.02 Dilation and curettage following delivery or abortion

69.09 Other dilation and curettage

69.41 Suture of laceration of uterus

69.52 Aspiration curettage following delivery or abortion

69.59 Other aspiration curettage of uterus

69.7 Insertion of intrauterine contraceptive device

70.29 Other diagnostic procedures on vagina and cul-de-sac

70.33 Excision or destruction of lesion of vagina

70.50 Repair of cystocele and rectocele

70.62 Vaginal reconstruction

70.73 Repair of rectovaginal fistula 
71.71 Suture of laceration of vulva or perineum

71.79 Other repair of vulva and perineum

13. OBSTETRICAL PROCEDURES (72-75)

73.59 Other manually assisted delivery

73.6 Episiotomy

74.1 Low cervical cesarean section

74.3 Removal of extratubal ectopic pregnancy

74.91 Hysterotomy to terminate pregnancy

74.99 Other cesarean section of unspecified type

75.4 Manual removal of retained placenta

75.51 Repair of current obstetric laceration of cervix

75.52 Repair of current obstetric laceration of corpus uteri

75.61 Repair of current obstetric laceration of bladder and urethra

75.62 Repair of current obstetric laceration of rectum and sphincter ani

75.69 Repair of other current obstetric laceration

14. OPERATIONS ON THE MUSCULOSKELETAL SYSTEM (76-84)

77.00 Sequestrectomy, unspecified site

77.05 Sequestrectomy, femur

77.07 Sequestrectomy, tibia and fibula

77.09 Sequestrectomy, other bones

77.60 Local excision of lesion or tissue of bone, unspecified site

77.65 Local excision of lesion or tissue of bone, femur

77.85 Other partial ostectomy, femur

78.15 Application of external fixator device, femur

78.17 Application of external fixator device, tibia and fibula

78.60 Removal of implanted devices from bone, unspecified site

79.01 Closed reduction of fracture without internal fixation, humerus

79.02 Closed reduction of fracture without internal fixation, radius and ulna

79.06 Closed reduction of fracture without internal fixation, tibia and fibula

79.25 Open reduction of fracture without internal fixation, femur

79.31 Open reduction of fracture with internal fixation, humerus

79.32 Open reduction of fracture with internal fixation, radius and ulna

79.71 Closed reduction of dislocation of shoulder

79.85 Open reduction of dislocation of hip

80.16 Other arthrotomy, knee

81.00 Spinal fusion, not otherwise specified

81.02 Other cervical fusion, anterior technique

81.05 Dorsal and dorsolumbar fusion, posterior technique

81.44 Patellar stabilization

81.46 Other repair of the collateral ligaments

81.52 Partial hip replacement

82.45 Other suture of other tendon of hand

83.09 Other incision of soft tissue

83.14 Fasciotomy

83.21 Biopsy of soft tissue

83.39 Excision of lesion of other soft tissue

83.49 Other excision of soft tissue 
83.64 Other suture of tendon

84.01 Amputation and disarticulation of finger 4

84.07 Amputation through humerus

84.10 Lower limb amputation, not otherwise specified

84.11 Amputation of toe

84.12 Amputation through foot

84.15 Other amputation below knee 6

84.17 Amputation above knee 15

84.3 Revision of amputation stump 6

15. OPERATIONS ON THE INTEGUMENTARY SYSTEM (85-86)

85.21 Local excision of lesion of breast $\quad 10$

85.41 Unilateral simple mastectomy $\quad 12$

86.04 Other incision with drainage of skin and subcutaneous tissue 73

86.09 Other incision of skin and subcutaneous tissue 2

86.11 Biopsy of skin and subcutaneous tissue 2

86.22 Excisional debridement of wound, infection, or burn 54

86.26 Ligation of dermal appendage 2

86.28 Nonexcisional debridement of wound, infection or burn 47

86.3 Other local excision or destruction of lesion or tissue of skin and subcutaneous tissue 17

86.59 Closure of skin and subcutaneous tissue of other sites $\quad 57$

86.60 Free skin graft, not otherwise specified 12

86.84 Relaxation of scar or web contracture of skin 3

86.89 Other repair and reconstruction of skin and subcutaneous tissue 3

16. MISCELLANEOUS DIAGNOSTIC AND THERAPEUTIC PROCEDURES (87-99)

87.65 Other $\mathrm{x}$-ray of intestine

93.51 Application of plaster jacket $\quad 7$

93.54 Application of splint $\quad 7$

93.57 Application of other wound dressing 4

97.02 Replacement of gastrostomy tube 2

98.02 Removal of intraluminal foreign body from esophagus without incision 31

98.11 Removal of intraluminal foreign body from ear without incision 13

98.13 Removal of intraluminal foreign body from pharynx without incision 7

98.14 Removal of intraluminal foreign body from larynx without incision 2

98.15 Removal of intraluminal foreign body from trachea and bronchus without incision 31

98.29 Removal of foreign body without incision from lower limb, except foot 2 